\title{
Ensaios sobre a Reforma Protestante à luz da teologia luterana
}

Marcio Simão de Vasconcellos ${ }^{1}$

O dia 31 de outubro de 2017 marca os 500 anos da Reforma Protestante, ocorrida no século XVI. A data é antecipada com uma expectativa de celebração por parte de muitas igrejas protestantes, mas também pelo desconhecimento que se tem da Reforma por parte de outras tantas igrejas. Martinho Lutero, o reformador alemão, é, ainda, e em grande medida, um desconhecido para várias tradições evangélicas, especialmente no Brasil. A herança da Reforma, os meandros dos acontecimentos que sucederam em um ritmo acelerado no século $\mathrm{XVI}$ na Europa, as consequências das teologias desenvolvidas a partir desse período, tudo permanece ainda muito obscuro para diversos cristãos, católicos ou protestantes. Apesar da existência de muitos estudos mais detalhados e compartilhados sobre o período da Reforma, ainda subsistem preconceitos de ambos os lados. As interpretações aplicadas a esse movimento ora elevam, ora abatem Lutero e seus seguidores como, respectivamente, salvadores ou destruidores da Igreja de Jesus. Como afirma Timothy George:

A historiografia católica tradicional retrata [Lutero] um monge louco, um psicótico demoníaco derrubando os pilares da Igreja Mãe. Para os protestantes ortodoxos, Lutero foi o cavaleiro divino, um Moisés, um Sansão (demolindo o templo dos filisteus!), um Elias, até mesmo o Quinto Evangelista e o Anjo do Senhor. ${ }^{2}$

Porém, nenhuma dessas caricaturas pode permanecer de pé caso se considere com seriedade "a própria autocompreensão de Lutero, que é onde uma avaliação satisfatória de sua teologia deve começar." ${ }^{3}$ Lutero sempre viu a si mesmo como um fiel e obediente servo da Igreja. Não desejava fundar nenhuma nova denominação. Exigia com veemência que as pessoas não se chamassem luteranas, mas cristãs. “Que é Lutero?”, exclamava, “O ensino não é meu. Nem fui crucificado por ninguém. [...] Como eu, miserável saco fétido de larvas que sou, cheguei ao ponto em que as pessoas chamam os filhos de Cristo por meu perverso nome?" ${ }^{4}$.

O caminho que percorreremos nesse artigo é o seguinte: a partir da análise do contexto histórico, cultural e, principalmente, religioso da Alta Idade Média, apresentaremos as crises teológicas de Lutero em suas constantes lutas para compreender a graça e a justiça de Deus. A partir daí, refletiremos sobre algumas consequências para a igreja contemporânea que a teologia luterana pode nos apresentar. A pergunta que norteará esse texto, portanto, é a seguinte: o que a Reforma Protestante, como movimento teológico e eclesiológico, pode contribuir para a vivência da fé cristã na contemporaneidade?

\footnotetext{
${ }^{1}$ Possui graduação em Teologia (Seminário Teológico Batista do Sul do Brasil e Universidade Metodista de São Paulo), é especialista em Ciências da Religião (FATERJ), mestre em Teologia Sistemático-Pastoral (PUC-RJ) e doutorando em Teologia Sistemático-Pastoral (PUC-RJ). Pesquisador na área do diálogo entre teologia e literatura fantástica.

${ }^{2}$ GEORGE, Timothy, Teologia dos reformadores, p. 55.

${ }^{3}$ Ibidem.

${ }^{4}$ Ibidem
} 


\section{O contexto da Reforma Protestante}

A vida e a obra de Lutero, refletidas em sua teologia, marcam o ponto decisivo da Reforma Protestante. Esta frase não é pretensiosa; antes, ressalta uma realidade, pois a Reforma só foi possível graças à "experiência de um monge agostiniano em sua cela

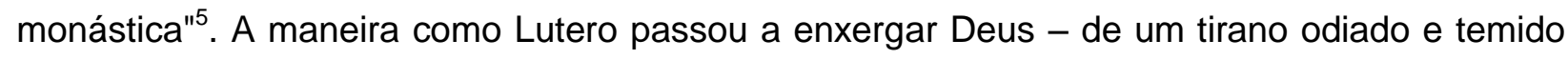
para um Deus de amor e misericórdia - confunde-se com a própria história da Reforma. Portanto, é a compreensão bíblica sobre a graça de Deus que marca todo esse processo histórico. A busca de Lutero para satisfazer a justiça divina em sua suposta ira contra o pecador, as suas crises de culpa e ansiedade, suas orações e vigílias constantes e desesperadas, tudo isso culmina nessa (re)descoberta da graça de Deus e da aceitação do ser humano proporcionada por Cristo.

Entretanto, qualquer evento histórico não pode ser estudado sem se levar em consideração os acontecimentos que o antecederam e que serviram como base para seu surgimento. A Idade Média foi chamada de Idade das Trevas pelos homens do Renascimento. Trata-se de um epíteto pejorativo: o período medieval não foi uma época de trevas absolutas. Antes, houve buscas por novas formas de se relacionar com Deus, e também críticas ao sistema religioso e cultural estabelecidos. No interior da própria Igreja Católica medieval havia diversas vozes que, em maior ou menor grau, levantavam-se contra as injustiças praticadas em nome da fé. Algumas dessas vozes foram silenciadas por torturas e morte.

A grande marca da Idade Média foi a ansiedade ${ }^{6}$. Esta sensação se dava em pelo menos dois níveis. Por um lado, a ansiedade era provocada pelo medo diante da morte e do sofrimento. Numa época em que milhares de pessoas morriam devido à fome e à peste (especialmente a Peste Negra que dizimou um terço da população europeia), a visão da morte se manifestava em todos os aspectos da cultura medieval: pinturas, esculturas, xilogravuras, e até mesmo os sermões traziam em si a ideia da morte, do sofrimento e do Juízo Final. Um dos quadros mais famosos da época, por exemplo, era a "Dança da Morte" que mostrava a morte, como um esqueleto, dançando e levando para as trevas tanto ricos quanto pobres. Em um dos cantos da pintura, uma ampulheta lembrava a fugacidade da vida e a inevitabilidade da morte.

Por outro lado, a ansiedade se revelava na sensação de culpa diante de um Deus Santo e Todo-Poderoso, do qual não se poderia esconder. Havia uma culpabilização exacerbada que era amparada pelo desenvolvimento de uma imagem de Deus distorcida pelo medo e pela culpa. Bem diferente do Abba de Jesus, o Deus desenvolvido pela teologia cristã desse período fazia, na prática, a justiça punitiva de Deus sobrepor-se à sua misericórdia e bondade. Predominava a imagem de um Deus de "olhos de lince", um Deus "infinitamente bom que,

\footnotetext{
${ }^{5}$ TILLICH, Paul, História do pensamento cristão, p. 227

${ }^{6}$ lbid., p. 228.
} 
entretanto, pune terrivelmente"7 e que "se manifestaria como vingador, quando do final do mundo e do correspondente julgamento", mas cujo castigo já era infligido ao ser humano no hoje. Segundo esta perspectiva, catástrofes naturais, epidemias, pestes, e inclusive o juízo final, tema de diversas obras de arte medievais, eram devidos ao rompimento da ordem estabelecida por Deus pelos seres humanos. O leitmotiv, usado para interpretar a vida e suas crises, era o Deus que, por não suportar o pecado, também não suportará o pecador por muito mais tempo: "Terrível coisa é cair nas mãos do Deus vivo!" (Hb 10,31) .

\begin{abstract}
O horizonte, sempre presente, do profundo desprezo pelo mundo atual, a insistência na enormidade do pecado humano, a imagem de um Deus irado e vingativo, em quem a justiça punitiva sobressai sobre a misericórdia, só podiam levar a uma enorme culpabilização (...) Esta superculpabilização é decorrente do fato de que a realidade do pecado foi muito mais ressaltada, na época estudada, do que a experiência do perdão. E isto em conexão, claro está, com a imagem prevalecente de Deus: justo e castigador em detrimento de sua bondade e misericórdia. ${ }^{10}$
\end{abstract}

Nesta realidade cultural e teológica, o medo produzia a culpa e esta alimentava o medo, num círculo vicioso cada vez mais intenso. Ora, diante dessa situação, isto é, diante de uma redenção que não redime, os únicos caminhos possíveis são o desespero ou a hipocrisia, ambas atitudes presentes na vida espiritual da Idade Média (e também em nossos dias).

O próprio esforço da teologia e prática pastoral da Idade Média tardia no
sentido de oferecer segurança somente fez levar um mundo já inseguro a uma
insegurança e incerteza ainda maiores no tocante à salvação. Uma das ideias
escolásticas centrais que levaram a essa incerteza com respeito à salvação
exprimia-se na expressão facere quod in se este: faz o que está ao teu
alcance; faz o melhor que podes. A expressão significava que o empenho de
amar a Deus da melhor maneira possível - por mais fraco que ele pudesse ser
- levaria Deus a recompensar os esforços da pessoa em questão com a graça
de agir e fazer ainda melhor. ${ }^{11}$

Assim, os esforços para dar sempre este melhor a Deus - esforço este que garantiria a sua graça - se multiplicaram de forma exponencial. Afinal, a pergunta que as pessoas da Idade Média, e especialmente os mais espiritualmente sensíveis, faziam era: "Como posso saber se fiz o melhor que pude?". Como ter a certeza da aceitação de Deus se a única garantia era o próprio procedimento que, em toda autoanálise, sempre poderia ser melhorado? A lógica teológica do período conjugava os termos "se - então": se a pessoa fosse justa ou boa da melhor maneira possível, então poderia receber a graça divina. Uma consequência direta desse tipo de mentalidade foram os inúmeros instrumentos compreendidos como meios para conquistar a aceitação de Deus. A autoflagelação pública, com chicotes de couro; as peregrinações a lugares santos; as relíquias; a veneração dos santos; a adoração da hóstia consagrada; a repetida reza do Pai Nosso, e, é claro, as indulgências (elemento central às

\footnotetext{
${ }^{7}$ DELUMEAU, Jean, O pecado e o medo: a culpabilização no Ocidente (séculos 13-18), volume II, p. 143.

${ }^{8}$ RUBIO, Alfonso Garcia, A caminho da maturidade na experiência de Deus, p. 191.

9 DELUMEAU, Jean, O pecado e o medo: a culpabilização no Ocidente (séculos 13-18), volume II, p. 152.

${ }^{10} \mathrm{RUBIO}$, Alfonso Garcia, A caminho da maturidade na experiência de Deus, p. 193.

${ }^{11}$ LINDBERG, Carter, As reformas na Europa, p. 78
} 
críticas de Lutero em suas 95 Teses), tudo representava os esforços humanos para aliviar a culpa e aumentar a garantia da salvação eterna.

\section{Martinho Lutero e a justiça de Deus revelada no Evangelho}

Não é possível apresentar a vida de Lutero nessas poucas linhas. O que faremos é delinear algumas de suas questões e crises como bússolas orientadoras para compreendermos a teologia luterana que nasceu da Reforma Protestante. É essencial estudarmos a vida de Lutero, pois, como já foi proposto, é ele o causador inicial de um movimento religioso que dividiu a Europa e o mundo.

Martinho Lutero nasceu em 10 de novembro de 1483, na cidade de Eisleben, filho de um minerador de prata da classe média. Seu nome era Martin Lüder, e somente mais tarde, como fruto de uma nova compreensão teológica, ele alterou seu sobrenome para Lutero (a palavra Lutero surge da palavra grega eleutheria, que significa liberdade). Seu pai desejava que Lutero estudasse Direito a fim de progredir materialmente: "Ele enviara Martinho à Universidade de Erfurt com a ambição de que este obteria um título na área de direito, retornaria para casa, na cidade de Mansfeld, e talvez acabasse se tornando seu prefeito."12. Mas durante uma forte tempestade, no dia 2 de julho de 1505, Lutero quase foi atingido por um raio. É nesse momento que, em desespero, Lutero grita: "Salva-me, Santa Ana, e serei monge!". Após essa experiência, Lutero ingressou em um mosteiro de tradição agostiniana. Lá, "lançou-se com toda a dedicação aos esforços para obter a salvação. Entre as seis celebrações religiosas de cada dia, que começavam às 2 horas da manhã, ele encaixou sessões de oração, meditação e exercícios espirituais intensos." ${ }^{13}$. Seus exercícios espirituais quase o matavam (literalmente!); seus esforços constituíam verdadeiras sessões de tortura às quais Lutero se entregava com avidez, medo e culpa sempre crescentes.

Como vimos, Lutero estudou Direito, antes de estudar Teologia, e é como perito em Direito que ele entendia a justiça de Deus. Por isso, ao ler o texto de Romanos 1.17 - "A justiça de Deus se revela no evangelho, de fé em fé, como está escrito: o justo viverá pela fé" - Lutero não podia compreender como o Evangelho, sendo boa-nova, poderia ser relacionado à justiça de Deus que pune os maus, isto é, todas as pessoas. Esta é a imagem que Lutero tinha acerca de Deus: eternamente irado contra o pecador, e absolutamente inatingível. Daí, suas constantes crises e depressões profundas, aliado a um ódio cada vez maior por Deus. Como ele mesmo afirmou: "Eu não amava, na verdade odiava aquele Deus que punia os pecadores; e com um murmurar monstruoso, silencioso, se não blasfemo, enfureci-me contra Deus."14.

Lutero vivia num mosteiro com essa mesma ansiedade, em face da culpa e da ameaça da condenação. Foi por causa dela que se internou no mosteiro e foi também por sua causa que descobriu que nenhuma quantidade de práticas

\footnotetext{
12 lbid., p. 83

13 Ibidem.

${ }^{14}$ LUTERO apud GEORGE, Timothy, Teologia dos reformadores, p. 64
} 
ascéticas conseguia dar às pessoas a certeza da salvação num sistema de relatividades, quantidades e coisas. Estava sempre com medo do Deus ameaçador, do Deus punitivo e destruidor. E perguntava: Onde posso encontrar o Deus misericordioso? ${ }^{15}$

Esse medo de Deus explica sua revolta interior: Lutero ia do desespero por seus pecados à ira contra Deus e de volta ao desespero. Em sua análise, Deus se assemelhava a um Ser que colocava diante do homem uma tarefa impossível de ser realizada, e, depois, zombava da incapacidade deste homem em cumpri-la. E Lutero esforçou-se como poucos para tentar cumprir esta tarefa e aplacar a ira divina. Seu líder na ordem agostiniana, Johann von Staupitz, testemunhou de perto este esforço, e se tornou seu grande conselheiro espiritual. Em parte, graças a ele é que Lutero construiu sua teologia. Se para receber o perdão divino, todos os pecados deveriam ser declarados na confissão, Lutero vivia atormentado pelo medo de se esquecer de algum deles. Assim, Lutero se confessava a Staupitz durante horas, ia embora e depois voltava correndo com alguma pequena fraqueza que havia esquecido de mencionar. Certa vez, Staupitz, bastante exasperado, disse: 'Olhe aqui, irmão Martinho. Se você vai confessar tanto assim, por que não faz algo digno de ser confessado? Mate sua mãe ou seu pai! Cometa adultério! Pare de vir aqui com tais tolices e pecados falsos!"'16

A solução para essa crise teológica e existencial, compartilhada com seus contemporâneos, só veio quando Lutero se deteve na segunda parte do versículo de Romanos: "o justo viverá pela fé". Lutero compreendeu, então, que fé se assemelha à mesma confiança que uma criança tem em seu pai, quando se joga em seus braços. Em outras palavras, se somos salvos, isto é exclusiva obra de Deus, não nossa. Assim, Deus é justo, e preside o tribunal de julgamento; mas também é réu, justificando o homem. Na relação homem-Deus, a teologia luterana afirma que o homem é aceito pelo Senhor, independentemente das coisas que faça ou deixe de fazer. Não se trata, portanto, de uma relação quantitativa (quantas coisas devemos fazer para apaziguar a ira divina), mas sim, qualitativa (a aceitação pessoal do fato de que já somos aceitos por Deus, graças à Cruz de Cristo, isto é, à justiça de Deus revelada no Evangelho, que, agora sim, pode ser chamado de "boa-nova"). Assim, a justificação pela graça "modifica a linguagem da teologia de uma estrutura de 'se (...) então' para uma estrutura de 'porque (...) portanto'; de uma linguagem de condições a serem cumpridas a fim de receber o que quer que seja prometido para uma linguagem da promessa incondicional."17

A resolução desta crise coincidiu com o ataque de Lutero aos exageros relacionados às indulgências. Johannes Tetzel, um frade dominicano contemporâneo de Lutero, defendia a ideia de que "no momento em que o dinheiro na caixa tinir, do purgatório ao céu salta a alma a seguir" $^{18}$. Suas pregações e apelos para a compra das indulgências elevaram a arte da homilética a um novo patamar. Suas descrições vívidas pintavam os horrores do inferno e do

\footnotetext{
${ }^{15}$ TILLICH, Paul, História do pensamento cristão, p. 229.

${ }^{16}$ GEORGE, Timothy, Teologia dos reformadores, p. 66

${ }^{17}$ LINDBERG, Carter, As reformas na Europa, p. 90

18 lbid., p. 96
} 
purgatório com tanta intensidade que seus ouvintes atropelavam-se na compra das indulgências a fim de fugir da vindoura ira divina. Aliás, dizia-se que "uma indulgência papal 'poderia absolver um homem mesmo que tivesse violado a mãe de Deus, caso isso fosse possível."'19. Alimentada por esse tipo de pregação, a venda de indulgências alcançou níveis elevadíssimos, gerando muito dinheiro que foi usado para a construção da Basílica de São Pedro, em Roma. Lutero reagiu contra esse tipo de ensinamento através das suas famosas 95 Teses, nas quais criticou o sistema de penitência conforme praticado e ensinado por Tetzel. Em uma dessas teses, de número 82, Lutero questionava: se a intenção das indulgências era retirar as almas do purgatório, por que o próprio papa não o esvaziava por um santíssimo ato de amor e das grandes necessidades das almas? Isto, pergunta ele, "não seria a mais justa das causas, visto que ele resgata um número infinito de almas por causa do sórdido dinheiro dado para a edificação de uma basílica, que é uma causa bem trivial?"20. Além disso, Lutero defendia que o papa não tinha o "poder de perdoar a culpa a não ser declarando ou confirmando que ela já havia sido perdoada por Deus" ${ }^{21}$.

É preciso perceber que o que sustenta essas críticas é uma nova imagem de Deus, mais vinculada à graça e misericórdia reveladas em Jesus de Nazaré. A busca pelo Deus misericordioso ${ }^{22}$ dos evangelhos era o combustível que Lutero queimava em suas novas posturas e reflexões teológicas.

\section{Algumas implicações da Reforma Protestante para nosso tempo}

O evangelho significa boa notícia. Porém, nem sempre ele se torna, de fato, uma boa nova na vida das pessoas que nos cercam. Hoje, ainda corremos o risco de reproduzir a crença em uma imagem de Deus distorcida, bastante semelhante à que dominava a sociedade medieval. É preciso repensar nossa teologia e, à luz do revelador de Deus por excelência Jesus de Nazaré - revisarmos nossas eclesiologias, liturgias, sacramentos etc. Nesse sentido, a teologia luterana nos auxilia muito.

Desenvolvida no chão da vida, no confronto com os problemas, as tentações, as lutas e as crises do cotidiano, a teologia luterana parte dessa revelação da graça de Deus em Jesus e no Jesus que se entrega para servir e perdoar. Daí a ênfase na Pessoa de Cristo, sobretudo o Cristo na cruz. Para Lutero, a maneira de entender a Deus é olhando para a cruz. O rosto de Deus é o rosto desfigurado da cruz por amor ao ser humano. A revelação de Deus só vem ao homem por meio da cruz, e fora dela, seríamos todos cegos e todos os nossos altares carregariam o nome Ao Deus Desconhecido (cf. At 17.23). "Portanto, meu querido irmão", escreveu Lutero, "aprenda Cristo e o aprenda crucificado; aprenda a orar a ele, perdendo toda

\footnotetext{
${ }^{19}$ Ibid., p. 97

${ }^{20}$ BETTENSON, H., Documentos da Igreja cristã, p. 289

${ }^{21}$ lbid., p. 282

${ }^{22}$ Cf.: TILLICH, Paul, História do pensamento cristão, p. 229
} 
esperança em si mesmo, e diga: 'Tu, Senhor Jesus, és a minha justiça, e eu sou o teu pecado. Tomaste em ti mesmo o que não eras e deste-me o que não sou'."23

Essa ênfase cristocêntrica está intimamente relacionada àquela que, possivelmente, é a principal característica da teologia luterana: a confiança plena na graça de Deus. Para Lutero, esta graça era de Deus, e não da Igreja. Em outras palavras, não poderia ser comprada, vendida ou negociada por meio das indulgências. "Deixem Deus ser Deus!", era seu grito reformador. Se o "justo viverá pela fé", então a salvação humana é obra exclusiva de Deus, e não provém de quaisquer esforços do homem. Dessa forma, a relação com Deus não ocorre nas bases da meritocracia, mas por pura gratuidade divina. Tal como ocorre com o publicano da parábola de Jesus (LC 18.9-14), diante de Deus só se pode confessar a própria miséria e, ao mesmo tempo, confiar apenas e tão somente no caráter gracioso de Deus que, em Jesus, ama, sustenta e justifica o ser humano.

É difícil mensurar completamente a importância deste conceito teológico para a vida da igreja, mas é possível perceber uma consequência imediata dele: adotar a percepção luterana da graça implica em desistir de monopolizar o acesso ao Sagrado, conduz a desinstalar-se das cátedras de juízo contra o próximo, leva a repudiar ao papel de porteiros do reino de Deus, como se fôssemos nós os responsáveis em separar o joio do trigo. Por fim, assumir na fé esse Sola Gratia luterano auxilia-nos em enxergar Deus com olhos amorosos e não repletos de medo e culpa. Como afirma Gesché:

\begin{abstract}
Seria muito interessante que depois do "Livrai-nos do mal" fosse acrescentado no fim do pai-nosso: "Livrai-nos do medo". Assim como em relação à fatalidade, o cristianismo é um anúncio de não viver o temor e não nos deixarmos conduzir por ele. Dessa relação totalmente nova e extraordinária com Deus nasce um ser humano novo e libertado (...) Quando são João define Deus como amor (ver 1Jo 4,8.16), trata-se - já não nos damos conta disso - de uma verdadeira transgressão a todas as ideias habituais sobre Deus. Eis que Deus já não é um Deus que ameaça. ${ }^{24}$
\end{abstract}

\title{
Para refletir:
}

1. Outros movimentos reformadores antecederam a Reforma Protestante iniciada por Martinho Lutero. Você conhece alguns desses movimentos?

2. Como e em que sentido podemos repetir os mesmos erros da espiritualidade medieval hoje em dia? Será que a imagem de Deus que sustenta nossa vida está, de fato, relacionada a Jesus de Nazaré?

\section{Referências bibliográficas}

BETTENSON, H.. Documentos da Igreja cristã. 4aㅡ edição. São Paulo: ASTE, 2001.

DELUMEAU, Jean. O pecado e o medo: a culpabilização no Ocidente (séculos 13-18). Volume 2. São Paulo: EDUSC, 2003.

GEORGE, Timothy. Teologia dos reformadores. São Paulo: Vida Nova, 1993.

\footnotetext{
${ }^{23}$ GEORGE, Timothy, Teologia dos reformadores, p. 71

${ }^{24}$ GESCHÉ, Adolphe, O Cristo. Coleção Deus para pensar. Volume 6, p. 44.
} 
GESCHÉ, Adolphe. O Cristo. São Paulo: Paulinas, 2004. Coleção Deus para Pensar, vol. 6. LINDBERG, Carter. As reformas na Europa. São Leopoldo: Sinodal, 2001.

RUBIO, Alfonso Garcia. A caminho da maturidade na experiência de Deus. São Paulo: Paulinas, 2008.

TILLICH, Paul. História do pensamento cristão. 3aㅡ edição. São Paulo: ASTE, 2004. 